Check for updates

Cite this: RSC Adv., 2019, 9, 20786

Received 24th March 2019

Accepted 21st June 2019

DOI: 10.1039/c9ra02256b

rsc.li/rsc-advances

\section{QM/MM studies on luminescence mechanism of dinuclear copper iodide complexes with thermally activated delayed fluorescence $\uparrow$}

\author{
Qian Wang, ${ }^{a}$ Yuan-Jun Gao, ${ }^{a}$ Ting-Ting Zhang, (D)*ab Juan Han*a \\ and Ganglong Cui $\mathbb{D}^{a}$
}

The QM/MM method is employed to investigate the photophysical mechanism of two dinuclear copper iodide complexes with thermally activated delayed fluorescence (TADF). The $S_{1}-T_{1}$ energy differences $\left(\Delta E_{\mathrm{ST}}\right)$ in these two complexes are small enough so that repopulating the $\mathrm{S}_{1}$ state from $\mathrm{T}_{1}$ becomes energetically allowed. Both forward and reverse intersystem crossing (ISC and rISC) processes are much faster than the corresponding radiative fluorescence and phosphorescence processes $\left[k_{I S C}\left(10^{8} \mathrm{~s}^{-1}\right)>\right.$ $\left.k_{r}^{\mathrm{F}}\left(10^{6} \mathrm{~s}^{-1}\right), k_{\mathrm{rISC}}\left(10^{5} \mathrm{~s}^{-1}\right)>k_{\mathrm{r}}^{\mathrm{P}}\left(10^{3} \mathrm{~s}^{-1}\right)\right]$. The faster rISC process than the phosphorescence emission enables TADF. Moreover, the diphosphine ligands are found to play an important role in regulating the electronic structures and thereto the radiative and nonradiative rate constants. The present work rationalizes experimental phenomena and helps understand the intrinsic luminescence properties. The obtained insights could be useful for tuning the luminescence performance of dicopper-based luminescence materials.

\section{Introduction}

As third generation emitting materials, organic and inorganic compounds with thermally activated delayed fluorescence (TADF) have been extensively studied in recent decades. ${ }^{1-9}$ Due to the use of inexpensive $\mathrm{Cu}$ metal, a large variety of luminescent $\mathrm{Cu}(\mathrm{I})$ compounds have been investigated since TADF was observed in $\mathrm{Cu}(\mathrm{I})$ complexes by Blasse and co-workers in $1980 .{ }^{10}$ In addition, TADF $\mathrm{Cu}(\mathrm{I})$ materials exhibit certain superior luminescence properties, for example, they harvest all singlets and triplets for the generation of light in organic light emitting diodes (OLEDs). The first successful application as emitting materials in OLEDs was reported in 1999.11 Nowadays several classes of important structures that include three- and fourcoordinated mononuclear, and four-coordinated dinuclear $\mathrm{Cu}(\mathrm{I})$ complexes have been applied in commercial OLEDs. ${ }^{12}$ These complexes usually have distorted tetrahedral geometries around central $\mathrm{Cu}(\mathrm{I})$ atoms with diimine and diphosphine ligands. These quasi-tetrahedral structures often lead to low quantum yields due to efficient non-radiative decays. To

${ }^{a}$ Key Laboratory of Theoretical and Computational Photochemistry, Ministry of Education, College of Chemistry, Beijing Normal University, Beijing 100875, P. R. China.E-mail: zhangtt@bnu.edu.cn; hanjuan@bnu.edu.cn

${ }^{b}$ Key Laboratory of Magnetic Molecules and Magnetic Information Materials of Ministry of Education, School of Chemistry and Materials Science, Shanxi Normal University, Linfen 041000, P. R. China

$\dagger$ Electronic supplementary information (ESI) available. See DOI: 10.1039/c9ra02256b overcome this weakness a proposal of adopting binuclear $\mathrm{Cu}(\mathrm{I})$ complex structure was put forward, because similar structures between ground and emissive excited states in binuclear $\mathrm{Cu}(\mathrm{I})$ complexes result in an efficient emission. ${ }^{13}$

As a result, dinuclear $\mathrm{Cu}(\mathrm{I})$ complexes with monodentate or chelating phosphines have gained high experimental attention in the past decade. ${ }^{14,15}$ In 2007 the first device using iodobridged complexes was reported. ${ }^{16,17}$ In 2010 Deaton et al. reported a diamond core dinuclear $\mathrm{Cu}(\mathrm{I})$ complex with high TADF emission, which is comparable to high-performance phosphorescent emitting complexes with rare metals. ${ }^{18}$ Yersin et al. synthesized another dinuclear complex, which has a butterflyshaped metal-halide core that leads to a small $\Delta E_{\mathrm{ST}}$ of $0.05 \mathrm{eV}$ for TADF emission. ${ }^{19}$ Later, they further prepared some attractive shorter-lived halide-bridged dicopper TADF compounds with chelating aminophosphane ligands. ${ }^{20}$ The latest dinuclear $\mathrm{Cu}(\mathrm{I}) \mathrm{TADF}$ materials exhibit suitably short decay times and realize highly efficient OLEDs. ${ }^{20}$ These bridges are often unstable especially in fluid environments, which however can be enhanced by bridging two $\mathrm{Cu}(\mathrm{I})$ centers with additional bidentate ligands. ${ }^{21}$

On the other hand, it is commonly known that TADF is highly sensitive to structural details of emitting materials. To achieve better performance it is usually needed to effectively restrict certain vibration modes of emitting molecules, for example, recently reported efficient TADF of mononuclear tetradentate $\mathrm{Cu}(\mathrm{I})$ complexes. ${ }^{22}$ However, the corresponding studies on dinuclear copper complexes are less studied. It is not clear whether the introduced bidentate ligands restrict certain 
vibrational modes of dinuclear $\mathrm{Cu}(\mathrm{I})$ complexes leading to efficient TADF.

Recently, Kato et al. have synthesized solution-stable luminescent dinuclear $\mathrm{Cu}(\mathrm{I})$ complexes i.e. $\mathrm{Cu}_{2}(\mu-\mathrm{I})_{2}(\mathrm{dpppy})_{2}$ [dpppy $=2,3$-bis(diphenylphosphino)pyridine] (Cu-py) using chelating diphosphine ligands with heteroaromatic rings. ${ }^{9}$ These compounds were found to exhibit interesting TADF phenomena from mixed $(M+X) L C T$ excited singlet and triplet states. Further analysis clearly shows the molecular structure is almost identical to the parent $\mathrm{Cu}_{2}(\mu-\mathrm{I})_{2}(\mathrm{dppb})_{2}$ [dppb $=1,2$-bis(diphenylphosphino)benzene] (Cu-bz). ${ }^{16}$ The emission quantum yields of $\mathrm{Cu}-\mathrm{bz}$ and $\mathrm{Cu}$-py are measured to be 0.99 and 0.48 in the solid state at $298 \mathrm{~K}$, respectively. The $548 \mathrm{~nm}$ emission wavelength of $\mathrm{Cu}$-py is also redshifted compared to the $497 \mathrm{~nm}$ one of $\mathrm{Cu}-\mathrm{bz}$. In previous studies, these emission properties are simply discussed, but, detailed excited-state properties and underlying photophysical processes related to TADF, for example, forward and reverse intersystem crossing rates, competition between radiative and nonradiative transitions, are elusive and not explored computationally.

In this work we have carried out a comprehensive computational study on two dinuclear $\mathrm{Cu}(\mathrm{I})$ complexes $\left[\mathrm{Cu}_{2}(\mu-\right.$ $\left.\mathrm{I})_{2}(\mathrm{dppb})_{2}\right]$ (1) and $\left[\mathrm{Cu}_{2}(\mu-\mathrm{I})_{2}(\mathrm{dpppy})_{2}\right]$ (2) with chelating diphosphine ligands (see Fig. 1). Their excited-state geometric and electronic structures, forward and reverse intersystem crossing rates (ISC and rISC), fluorescence and phosphorescence emission rates are explored using both density functional theory (DFT) and time-dependent DFT (TD-DFT) methods in combination with the quantum mechanics/molecular mechanics (QM/MM) approach. In terms of the results, radiative and nonradiative rates and related TADF mechanism of these dinuclear $\mathrm{Cu}(\mathrm{I})$ TADF emitters are discussed in detail.

\section{Computational methods}

Initial models are built based on X-ray crystal structures in experiments. ${ }^{9}$ Full optimizations of crystal structures including cell parameters and molecular geometric parameters are carried out at the PBE level with periodic boundary condition (PBC). ${ }^{23}$ The DNP basis set is used to expand electronic wavefunction and the default dispersion correction of Grimme is added to consider weak dispersion interaction. ${ }^{24,25}$ A Monkhorst-Pack $k$ point grids of $2 \times 2 \times 2$ are used. Default convergence criteria on gradients and displacements are used in geometry optimizations. These calculations are performed using the $\mathrm{DMol}^{3}$ module in Materials Studio 2016. ${ }^{26-28}$

In order to simulate excited-state properties of these $\mathrm{Cu}(\mathrm{I})$ complexes in crystals, a combined quantum mechanics/

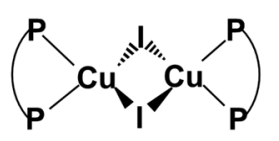

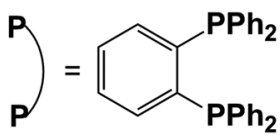

1

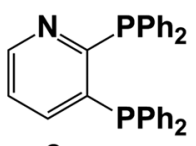

2
Fig. 1 Chemical structures of two Cu(I) complexes 1 and 2 studied in our present work. Also shown are two different substituent groups. molecular mechanics (QM/MM) method is used. ${ }^{29,30}$ The central one molecule is chosen as the QM region; whereas, the surrounding twelve molecules are chosen as the MM region and frozen during geometry optimizations (see Fig. S1†). The universal force field (UFF) and QM methods are used for the MM and QM regions, respectively. ${ }^{31}$ This strategy has been demonstrated to work well in previous works. ${ }^{32-34}$ The minima are optimized by the DFT $\left(S_{0}\right)$ and TD-DFT $\left(S_{1}\right.$ and $\left.T_{1}\right)$ methods with the hybrid exchange-correlation functional (PBE1PBE) ${ }^{35-37}$ In all these calculations, the Stuttgart relativistic pseudopotential and its accompanying basis set (SDD, ECP60MWB) are applied for the $\mathrm{Cu}$ and $\mathrm{I}$ atoms; the $6-31 \mathrm{G}^{*}\left[6-31+\mathrm{G}^{*}\right]$ basis set is used for $\mathrm{C}, \mathrm{H}$ and $\mathrm{N}[\mathrm{P}]$ atoms. ${ }^{38-41}$ All QM/MM geometry optimizations are carried out using Gaussian 09 (ref. 42) and all vibrational frequencies are calculated using Gaussian $16 .^{43}$ Oscillator strengths and spin-orbit coupling matrix elements that are used for rate constants of radiative fluorescence and phosphorescence emission and nonradiative ISC $\left(k_{\text {ISC }}\right)$ and ISC ( $\left.k_{\text {rISC }}\right)$ of compounds 1 and 2 are calculated using the Amsterdam density functional ADF program ${ }^{4-46}$ in which the TDPBE1PBE method and the TZP basis $\operatorname{set}^{47,48}$ are used with the zero order regular approximation (ZORA). ${ }^{\mathbf{4 9 - 5 1}}$

\section{Results and discussion}

\subsection{Molecular structure}

Important geometric parameters of two complexes in crystal as well as the corresponding experimental values are summarized in Table $\mathrm{S} 1 \dagger$ and optimized molecular structures in the $\mathrm{S}_{0}, \mathrm{~S}_{1}$, and $\mathrm{T}_{1}$ states are schematically shown in Fig. 2 .

In the $\mathrm{S}_{0}$ state, two complexes have similar molecular structures and the structural parameters in crystal are consistent with experimental values. ${ }^{9}$ It also confirms the reliability of the PBE1PBE functional and the QM/MM method used. As shown in Fig. 2, the $\mathrm{Cu}$ atoms in the two complexes are coordinated with the two $\mathrm{P}$ atoms from the diphosphine ligands that form five-membered ring chelates and exhibit highly distorted tetrahedral coordination. The $\mathrm{Cu}-\mathrm{I}$ and $\mathrm{Cu}-\mathrm{P}$ bond lengths are comparable in the two complexes in crystal. The $\mathrm{Cu} \cdots \mathrm{Cu}$ distance is well-known to exert an evident impact on photophysical properties of the polynuclear $\mathrm{Cu}(\mathrm{I})$ halide complexes and the short $\mathrm{Cu} \cdots \mathrm{Cu}$ distance, less than $2.7 \AA$, usually generates emissive cluster-centered excited states. ${ }^{52}$ In crystal, they are $2.783 \AA$ and $2.805 \AA$ for 1 and 2 , respectively. The distances are more or less equal to the sum of van der Waals radius of $\mathrm{Cu}(\mathrm{I})$ of $2.8 \AA$, indicating a small interaction between these two $\mathrm{Cu}$ atoms. The similar changes can be found in the $\mathrm{I} \cdots \mathrm{I}$ distances. These shortened distances should come from the influence of the surrounding molecules.

For 1 , both $\mathrm{I}-\mathrm{Cu}-\mathrm{I}$ and $\mathrm{P}-\mathrm{Cu}-\mathrm{P}$ bond angles deviate largely from the usual tetrahedral value of $109.5^{\circ}$. In particular, the P$\mathrm{Cu}-\mathrm{P}$ bond angles are only $88.3^{\circ}$ in crystal because of the small angle of the diphosphine ligand with respect to the fivemembered ring chelate. The value $90.0^{\circ}$ in crystal for compound 2 is larger slightly than that of compound $\mathbf{1}$. The chelate effect of diphosphine ligands may lead to stable complexes 1 and 2 . In addition, two $\mathrm{Cu}(\mathrm{I})$ centers are bridged by 

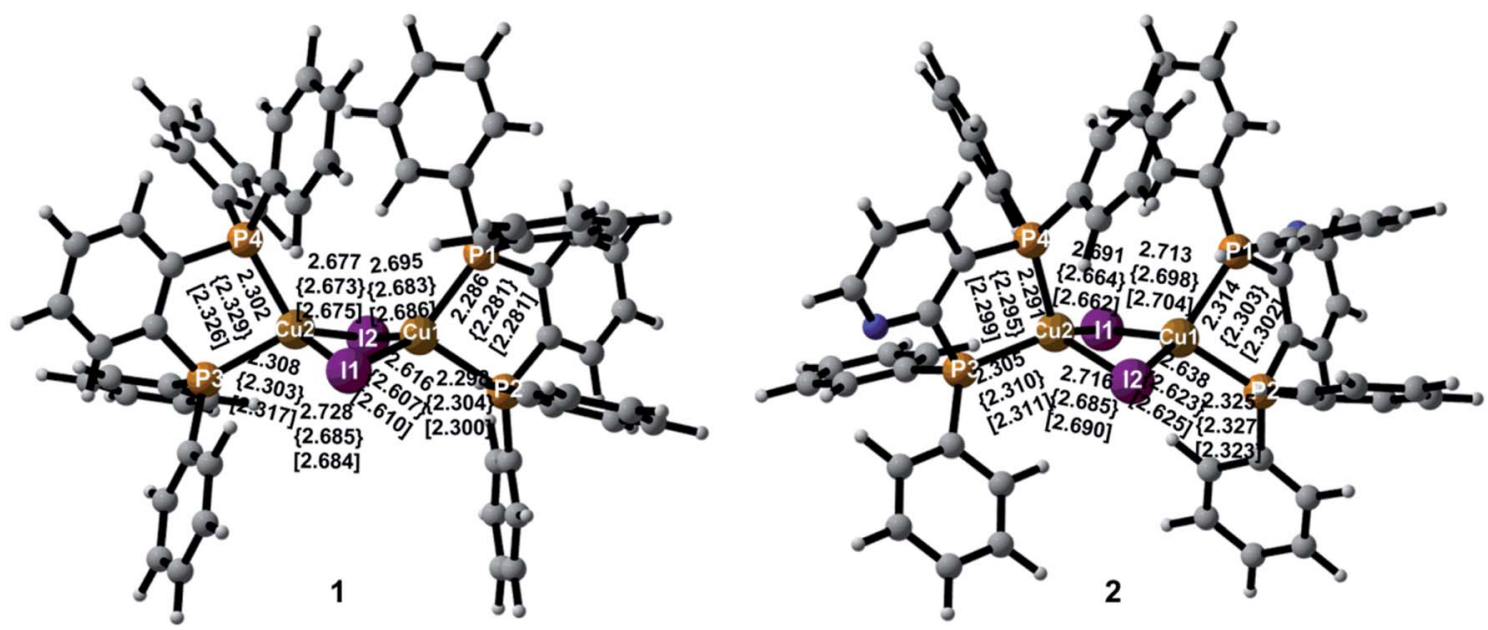

Fig. 2 Optimized minimum-energy structures with atomic numbering and selected geometric parameters in the $S_{0}, S_{1}$ \{curly brackets\}, and $T_{1}$ [square brackets] states.

two I atoms to form a dinuclear structure with a bent rhombic $\left\{\mathrm{Cu}_{2} \mathrm{I}_{2}\right\}$ core. The four-membered butterfly $\mathrm{Cu}_{2} \mathrm{I}_{2}$ rings of the complexes are significantly distorted by bending along the $\mathrm{I} \cdots \mathrm{I}$ axis, which is different from most of halide-bridged $\mathrm{Cu}(\mathrm{I})$ complexes having a planar rhombic $\mathrm{Cu}_{2} \mathrm{X}_{2}$ geometry. ${ }^{53,54}$ The dihedral angles between the two $\mathrm{CuI}_{2}$ triangles in the $\left\{\mathrm{Cu}_{2} \mathrm{I}_{2}\right\}$ core are $141.5^{\circ}$ and $144.1^{\circ}$ for 1 and 2 in crystal, respectively, implying a large steric hindrance of the diphenyl groups attached on the phosphines.

Different geometric changes of complexes 1 and 2 in the excited states are related to their luminescent properties. Comparing geometric parameters of $\mathrm{S}_{0}, \mathrm{~S}_{1}$, and $\mathrm{T}_{1}$ minima in crystal, we can see that the $\mathrm{Cu}-\mathrm{I}$ bond lengths and the $\mathrm{I} \cdots \mathrm{I}$ distances are shortened for $\mathbf{1}$ and 2 . The changes of the $\mathrm{Cu} \cdots \mathrm{Cu}$ distances are different from those of the $\mathrm{Cu}-\mathrm{I}$ bond lengths. For 1, they are computed to $2.918 \AA$ and $2.934 \AA$ in $\mathrm{S}_{1}$ and $\mathrm{T}_{1}$, respectively, which are longer than $2.783 \AA$ in $\mathrm{S}_{0}$. There are negligible changes for the $\mathrm{Cu}-\mathrm{P}$ bond lengths in $\mathrm{S}_{1}$ and $\mathrm{T}_{1}$. The same trend is also observed for compound 2. In addition, Fig. 3 displays the difference of geometric parameters for $\mathbf{1}$ and 2 between $S_{0}$ and $S_{1}\left(T_{1}\right)$ states. It is worth mentioning that the $S_{1}$ and $\mathrm{T}_{1}$ minima are structurally similar to each other, which may be caused by the dppb and dpppy ligands constructing a sterically bulky coordination environment around the $\mathrm{Cu}$ atoms. As a result, the structural distortion of the MLCT excited state may be suppressed,$^{55}$ which will benefit the $\mathrm{Cu}(\mathrm{I})$ complex to achieve high emission quantum yield, 0.99 for 1 and 0.48 for 2 in crystal. ${ }^{9}$ This corroborates experimental studies focused on the design of TADF for heteroleptic $\mathrm{Cu}(\mathrm{I})$ complexes. ${ }^{54,55}$

\subsection{Frontier molecular orbitals}

Frontier orbital analysis for compound $\mathbf{1}$ and its related orbital energies at the $S_{0}$ and $S_{1}$ minima are shown in Fig. 4. The frontier orbital characters of $\mathbf{1}$ and $\mathbf{2}$ at the $\mathrm{T}_{1}$ minima as well as those of 2 at the $S_{0}$ and $S_{1}$ minima are displayed in Fig. S2 and $\mathrm{S} 3, \dagger$ respectively.
As shown in the left panel of Fig. 4, the highest occupied molecular orbital (HOMO) of compound $\mathbf{1}$ at the $\mathrm{S}_{0}$ minimum is mainly derived from the $\mathrm{d}$ orbitals of the $\mathrm{Cu}$ centers and the $\mathrm{p}$ orbitals of the bridging I atoms. In contrast, the lowest unoccupied molecular orbital (LUMO) is localized at one dppb moiety of the bridging diphosphine ligands. The nature of molecular orbitals of compound $\mathbf{1}$ at the $\mathrm{S}_{1}$ minimum are almost constant except a little different weights from the different fragment groups (see the right panel of Fig. 4). The minimum-energy structures at both $S_{1}$ and $T_{1}$ states of $\mathbf{1}$ are similar to each other, thus subtly changes are found in the orbital analysis for the $\mathrm{T}_{1}$ minimum compared with that for the $\mathrm{S}_{1}$ one (see Fig. $\mathrm{S} 2 \dagger$ ). In addition, the calculations reveal that compositions for compound 2 at the $S_{0}$ and $S_{1}$ minima are almost identical with those of compound $\mathbf{1}$ and are thus placed in Fig. S3. $\dagger$

Since the photoexcited electron and the remaining hole are spatially separated in the $\pi^{*}$ orbital of the organic ligand and the $3 \mathrm{~d}$ orbital of the $\mathrm{Cu}$ atom, the energy gap between HOMO and LUMO tends to be small enough to permit an inverse intersystem crossing process from the $T_{1}$ to $S_{1}$ states enabling TADF. At the $\mathrm{S}_{0}$ minima, the HOMO-LUMO energy gaps are 4.07 and $3.97 \mathrm{eV}$ for compounds $\mathbf{1}$ and 2, respectively. However, they decrease to 3.30 and $3.14 \mathrm{eV}$ at the $\mathrm{S}_{1}$ minima and 3.26 and $3.15 \mathrm{eV}$ at the $\mathrm{T}_{1}$ minima for compounds 1 and 2 . Obviously, this remarkable reduction of the HOMO-LUMO energy gaps from the $S_{0}$ to $S_{1}$ minima of compounds $\mathbf{1}$ and $\mathbf{2}$ is responsible for the large Stokes shift experimentally observed in the emission spectra (see below, Fig. 5). On the other hand, the energy gap becomes smaller in compound $\mathbf{2}$ than that of $\mathbf{1}$, which is caused by the introduction of the pyridyl $\mathrm{N}$ atom with large electronegativity to the aromatic ring that stabilizes the $\pi^{*}$ orbitals. The similar variation of the HOMO-LUMO energy gaps is also found in recent theoretical works on dinuclear TADF $\mathrm{Cu}(\mathrm{I})$ molecules..$^{57}$ 

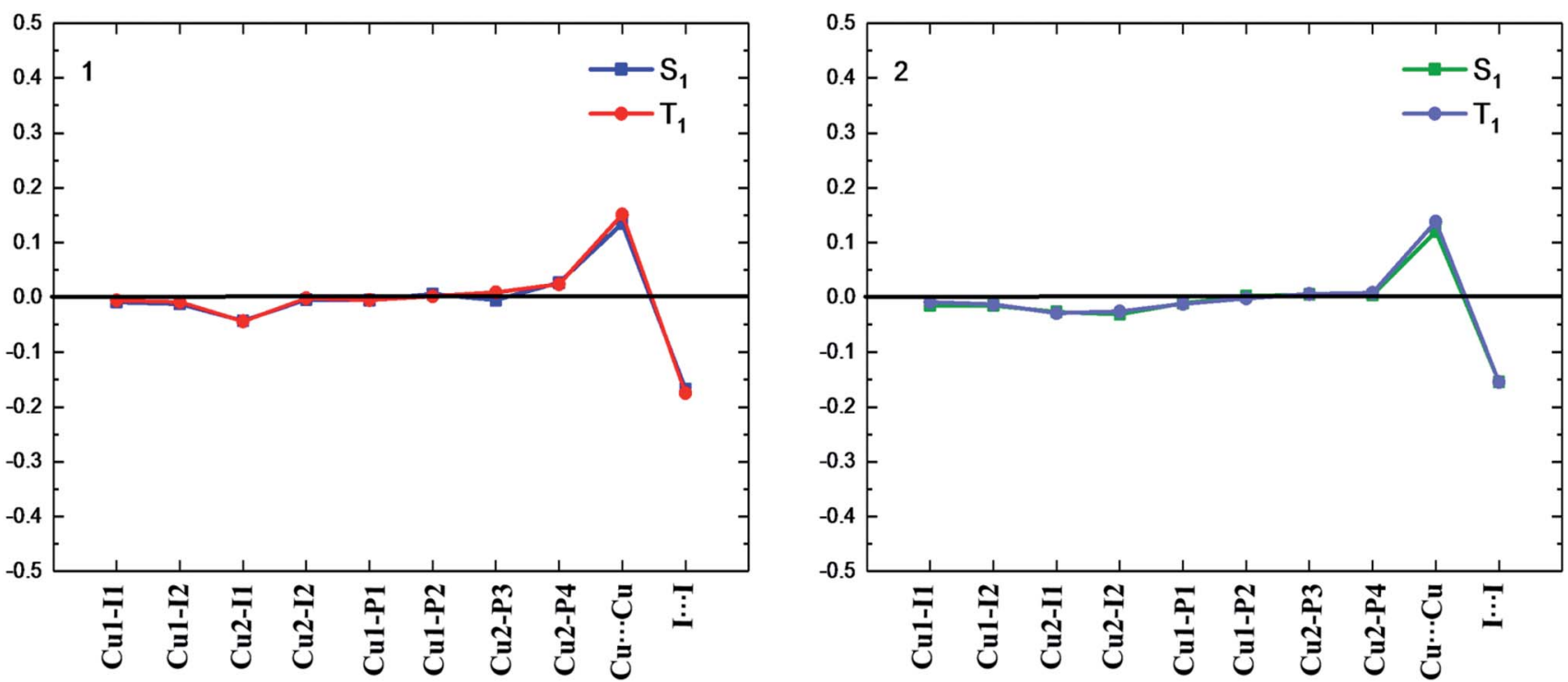

Fig. 3 Bond length differences (in $\AA$ ) of the $S_{1}$ and $T_{1}$ minima for complexes 1 and 2 relative to the counterparts of the $S_{0}$ minimum (black line).

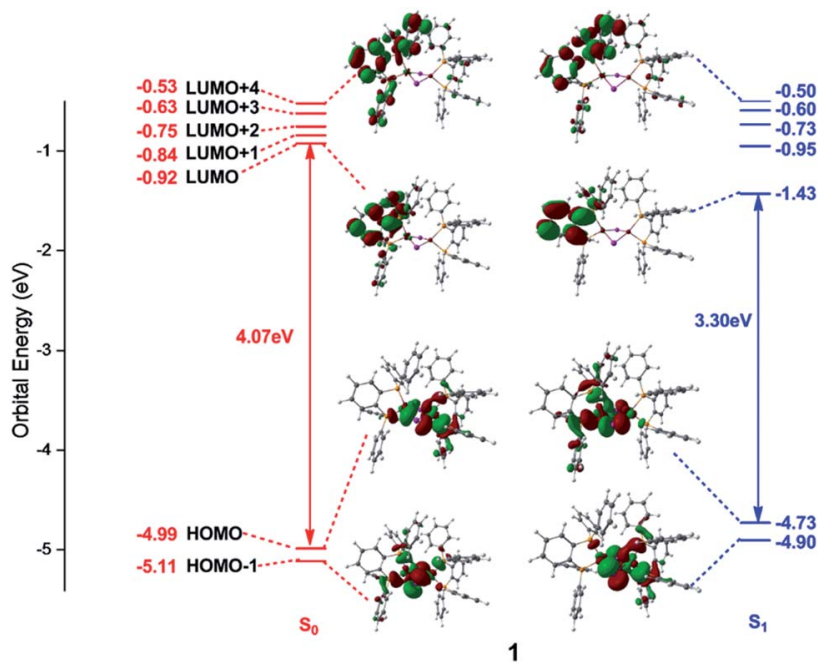

Fig. 4 Frontier molecular orbitals and related orbital energies (in eV) at the $S_{0}$ and $S_{1}$ minima of complex 1.

\subsection{Absorption spectra}

On the basis of the $S_{0}$ minima of compounds 1 and 2, we have simulated the corresponding absorption spectra. As shown in Fig. 5, there is a broad shoulder at ca. $400 \mathrm{~nm}$ in compound 1 . Electronic structure analysis shows that the absorption at $374 \mathrm{~nm}$ mainly stems from the $S_{0} \rightarrow S_{1}$ electronic excitation, for which the HOMO-LUMO electronic configuration contributes the most. The HOMO is mainly distributed over the $\mathrm{Cu}$ and I atoms, while the LUMO is localized on the dppb ligands. Thus, this absorption peak is of the mixed metal-to-ligand and halideto-ligand charge transfer $(\mathrm{M}+\mathrm{X}) \mathrm{LCT}$ character. The origin of the lowest absorption of compound $\mathbf{2}$ is similar to that of $\mathbf{1}$ and the calculated absorption of 2 at $392 \mathrm{~nm}$ has a small redshift compared to that of $\mathbf{1}$ at $374 \mathrm{~nm}$, which could be due to the stabilization of the $\pi^{*}$ orbitals of the bridging diphosphine ligands introduced by the pyridyl $\mathrm{N}$ atom.

For 1, the computed $331 \mathrm{~nm}$ peak is very close to the experimentally measured $330 \mathrm{~nm}$ peak in crystal. The $332 \mathrm{~nm}$ peak of $\mathbf{2}$ is almost equal to that in $\mathbf{1}$ and also reproduces the experimental value of $328 \mathrm{~nm} .{ }^{9}$ These peaks are mainly caused by the electronic excitation transitions of $S_{0} \rightarrow S_{8}$ for 1 and $S_{0}$ $\rightarrow \mathrm{S}_{10}$ for 2 . Moreover, these two complexes have strong absorption peaks at $291 \mathrm{~nm}$ (see Table S3†), which are also assigned to the electronic transitions $\mathrm{H} \rightarrow \mathrm{L}+1$ for 1 and $\mathrm{H}-1$ $\rightarrow \mathrm{L}+7$ for 2 , respectively. They are of the same electronic transition character i.e. $(\mathrm{M}+\mathrm{L}) \mathrm{CT}$ (see Fig. $\mathrm{S} 3 \dagger)$.

\subsection{Emission properties}

Vertical emission energies and related electronic configurations of compounds 1 and 2 in crystal from their $S_{1}$ and $T_{1}$ excited states are calculated and listed in Table 1, which also includes wavelengths and oscillator strengths. The corresponding fluorescence emission spectra based on the $S_{1}$ minima are simulated in Fig. 5.

In experiments, the emission spectrum of the dinuclear complex 1 in crystal is very similar to that of the mononuclear complex $\left[\mathrm{CuI}(\mathrm{dppb}) \mathrm{PPh}_{3}\right]\left(\lambda_{\mathrm{em}}=492 \mathrm{~nm}\right) .{ }^{16}$ This can be understood very well taking into account that the $\mathrm{Cu} \cdots \mathrm{Cu}$ distance of $\mathbf{1}$ is close to the sum of the van der Waals radii of two $\mathrm{Cu}$ atoms (see above). This results in very weak interaction between two $\mathrm{Cu}$ atoms in both ground- and excited-states; thus, the emission from 1 resembles that of the mononuclear complex. ${ }^{16}$

From Table 1, we can find that the HOMO-LUMO electronic configuration is predominantly responsible for the $S_{1} \rightarrow S_{0}$ and $\mathrm{T}_{1} \rightarrow \mathrm{S}_{0}$ electronic de-excitation transitions, which are also of mixed metal-to-ligand and halide-to-ligand charge-transfer character $(\mathrm{M}+\mathrm{X}) \mathrm{LCT}$. By contrast, the introduction of the $\mathrm{N}$ atoms to the cross-linking phenyl groups of the diphosphine 

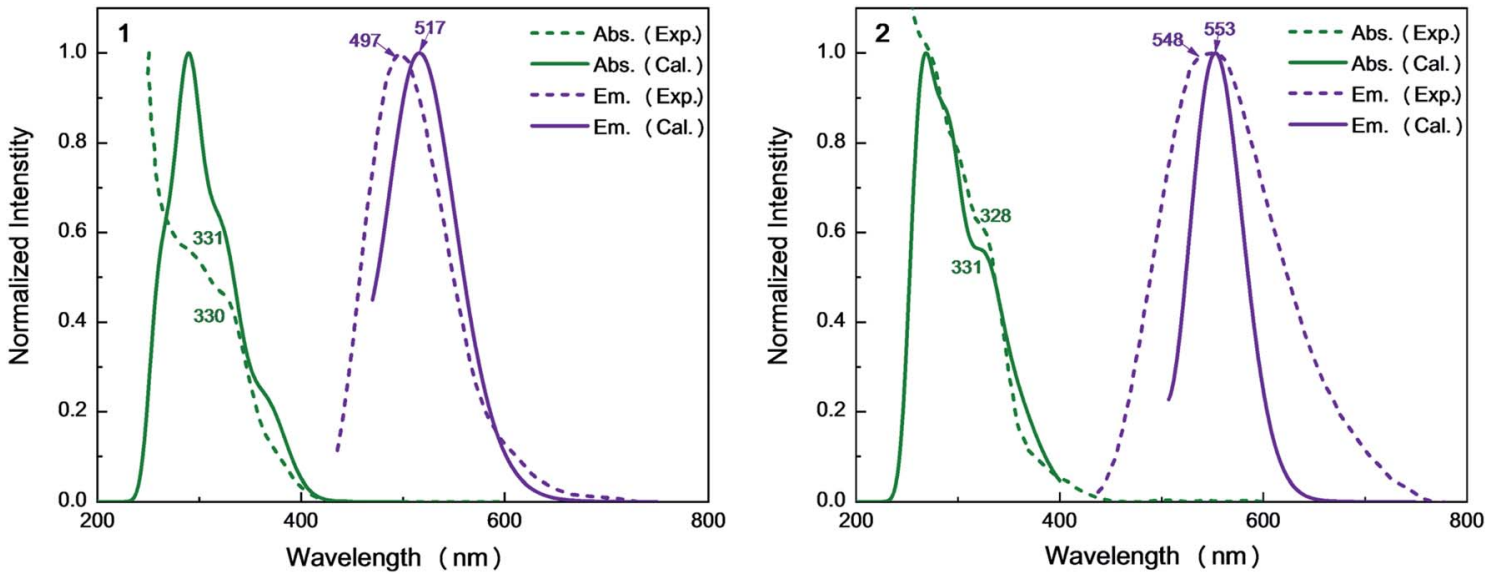

Fig. 5 Simulated absorption and emission spectra of complexes 1 and 2 with experimental results.

ligands in 2 greatly shifts the emission from bright-greenishblue $\left(\lambda_{\mathrm{em}}=497 \mathrm{~nm}\right)$ to yellow $\left(\lambda_{\mathrm{em}}=548 \mathrm{~nm}\right)$ as observed in experiments. ${ }^{9}$ The calculated $\lambda_{\max }$ values of the dinuclear complexes 1 and 2 are in the order $1(517 \mathrm{~nm})<2(553 \mathrm{~nm})$, which are consistent with the experimental values in crystal. ${ }^{9}$

\subsection{Excited state properties}

Excited-state properties play an important role in determining luminescence mechanism. In order to determine quantitatively related radiative and nonradiative processes of compounds 1 and 2, we have calculated rate constants of forward and inverse intersystem crossing processes between $\mathrm{S}_{1}$ and $\mathrm{T}_{1}\left[\operatorname{ISC}\left(k_{\mathrm{ISC}}\right)\right.$ and rISC $\left.\left(k_{\mathrm{rISC}}\right)\right]$ and those of fluorescence $\left(k_{\mathrm{r}}^{\mathrm{F}}\right)$ and phosphorescence $\left(k_{\mathrm{r}}^{\mathrm{P}}\right)$ from $\mathrm{S}_{1}$ and $\mathrm{T}_{1}$ in crystal.

3.5.1 ISC rate constants. The radiationless rate constants for the intersystem crossing processes are obtained by using the classical Marcus theory, ${ }^{58-60}$ which has been extensively used recently. ${ }^{61,62}$ Its basic formulae are briefly presented below to form a self-contained work. The rate constant from the initial i to final $\mathrm{f}$ electronic states is expressed by the classical Fermi golden rule:

$$
k_{\mathrm{i} \rightarrow \mathrm{f}}=\frac{2 \pi}{\hbar}\left|H_{\mathrm{if}}\right|^{2} \rho_{\mathrm{FC}}
$$

where $H_{\text {if }}$ is the effective spin-orbit coupling between the initial and final states. In the classical regime, this formula could be expressed by the famous Marcus equation where the FranckCondon weighted density of states, $\rho_{\mathrm{FC}}$, is written as

$$
\rho_{\mathrm{FC}}=\frac{1}{\sqrt{4 \pi \lambda_{\text {reorg }} k_{\mathrm{B}} T}} \exp \left[-\frac{\left(\Delta E+\lambda_{\text {reorg }}\right)^{2}}{4 \pi \lambda_{\text {reorg }} k_{\mathrm{B}} T}\right]
$$

in which $k_{\mathrm{B}}$ is the Boltzmann constant; $\Delta E$ is defined as the difference between adiabatic energies of the final and initial states; $T$ is the temperature; $\lambda_{\text {reorg }}$ is the Marcus reorganization energy. In terms of these formula, one can find that ISC $\left(k_{\mathrm{ISC}}\right)$ and rISC $\left(k_{\mathrm{rISC}}\right)$ rates are closely related to spin-orbit coupling (SOC) values, singlet-triplet energy differences $\left(\Delta E_{\mathrm{ST}}\right)$, and reorganization energies $\left(\lambda_{\text {reorg }}\right)$. In the next sections, we will discuss these factors separately to gain in-depth insights. The computed rate constants as well as spin-orbit coupling matrix elements (SOCMEs), and reorganization energies $\left(\lambda_{\text {reorg }}\right)$ are collected in Table 2.

Table 2 Spin-orbit coupling matrix elements (SOCMEs $/ \mathrm{cm}^{-1}$ ), reorganization energies $\left(\lambda_{\text {reorg }} / \mathrm{eV}\right)$, intersystem crossing rates $\left(k_{\mathrm{ISC}} / \mathrm{s}^{-1}\right)$, reverse intersystem crossing rates $\left(k_{\mathrm{rlsc}} / \mathrm{s}^{-1}\right)$, fluorescence rate constants $\left(k_{r}^{F} \times 10^{6} / \mathrm{s}^{-1}\right)$, and phosphorescence rate constants $\left(k_{r}^{\mathrm{P}} \times\right.$ $10^{3} / \mathrm{s}^{-1}$ ) of compounds 1 and 2 in crystal

\begin{tabular}{llllll}
\hline & At $\mathrm{S}_{1}$ & & & At $\mathrm{T}_{1}$ & \\
\cline { 2 - 3 } \cline { 5 - 6 } & $\mathbf{1}$ & 2 & $\mathbf{1}$ & \multicolumn{2}{l}{$\mathbf{2}$} \\
\hline SOCMEs $\left(\mathrm{cm}^{-1}\right)$ & 13.14 & 18.57 & 8.34 & 20.72 \\
$\lambda_{\text {reorg }}(\mathrm{eV})$ & 0.0256 & 0.0108 & 0.0241 & 0.0096 \\
$k_{\mathrm{ISC}} / k_{\mathrm{rISC}}\left(\mathrm{s}^{-1}\right)$ & $8.25 \times 10^{8}$ & $2.34 \times 10^{9}$ & $6.27 \times 10^{5}$ & $3.36 \times 10^{7}$ \\
$k_{\mathrm{r}}^{\mathrm{F}} \times 10^{6}\left(\mathrm{~s}^{-1}\right)$ & 3.91 & 0.33 & - & - \\
$k_{\mathrm{r}}^{\mathrm{P}} \times 10^{3}\left(\mathrm{~s}^{-1}\right)$ & - & - & 1.11 & 2.70
\end{tabular}

Table 1 Emission energies $(E / e V)$, wavelength $(\lambda / \mathrm{nm})$, oscillator strengths $(f)$, electronic configurations, and characters involved in the $\mathrm{S}_{1} \rightarrow \mathrm{S}_{0}$ and $T_{1} \rightarrow S_{0}$ electronic transitions of complexes 1 and 2 in crystal

\begin{tabular}{lllllll}
\hline & State & $E(\mathrm{eV})$ & $\lambda(\mathrm{nm})$ & $f$ & Electronic configuration & Assignment \\
\hline \multirow{1}{*}{$\mathbf{l}$} & $\mathrm{S}_{1}$ & 2.40 & 517 & 0.0157 & $\mathrm{H} \leftarrow \mathrm{L}(94.4 \%)$ & $(\mathrm{M}+\mathrm{X}) \mathrm{LCT}$ \\
& $\mathrm{T}_{1}$ & 2.19 & 567 & 0.0000 & $\mathrm{H} \leftarrow \mathrm{L}(93.1 \%)$ & (M + X)LCT \\
& $\mathrm{S}_{1}$ & 2.24 & 553 & 0.0015 & $\mathrm{H} \leftarrow \mathrm{L}(96.8 \%)$ & (M + X)LCT \\
& $\mathrm{T}_{1}$ & 2.14 & 579 & 0.0000 & $\mathrm{H} \leftarrow \mathrm{L}(93.3 \%)$ & $(\mathrm{M}+\mathrm{X}) \mathrm{LCT}$
\end{tabular}


First, we focus on the SOCMEs values of compounds 1 and 2 calculated at the $S_{1}$ and $T_{1}$ minima in crystal (see Table 2). After comparing these values, one can find that the SOC value $13.14 \mathrm{~cm}^{-1}$ of compound $\mathbf{1}$ at the $\mathrm{S}_{1}$ minimum is a little larger than that $8.34 \mathrm{~cm}^{-1}$ at the $\mathrm{T}_{1}$ minimum; but, the SOC value $18.57 \mathrm{~cm}^{-1}$ of compound 2 at the $S_{1}$ minimum is tinily smaller than $20.72 \mathrm{~cm}^{-1}$ at the $\mathrm{T}_{1}$ minimum. These SOCMEs values are comparable to other complexes with TADF and are large enough to ensure effective forward and reverse intersystem crossing processes.

Second, it is generally accepted that singlet-triplet energy difference $\left(\Delta E_{\mathrm{ST}}\right)$ is an important parameter to regulate reverse ISC processes. Table 3 lists the energies of the $S_{1}$ and $T_{1}$ minima of compounds 1 and 2 in crystal. One can see the $S_{1}$ and $T_{1}$ states' energies of compound 2 are a little decreased compared to those of compound 1. For example, the values $2.75 \mathrm{eV}$ in the $\mathrm{S}_{1}$ state and $2.66 \mathrm{eV}$ in the $\mathrm{T}_{1}$ state of compound 2 are smaller than $2.89 \mathrm{eV}$ and $2.74 \mathrm{eV}$ in $\mathrm{S}_{1}$ and $\mathrm{T}_{1}$ for compound 1 , respectively. Nevertheless, the $\Delta E_{\mathrm{ST}}$ values are still small in both compounds, i.e. $0.15 \mathrm{eV}$ in 1 and $0.09 \mathrm{eV}$ in 2 . Considering that both 1 and 2 have small $\Delta E_{\mathrm{ST}}$ values, which make their rISC processes from the $T_{1}$ to $S_{1}$ states possible in the view of energy. Meanwhile, we have also calculated higher-lying triplet excited states to judge whether they are also involved in TADF. From Table $\mathrm{S} 2, \dagger$ it is clear that there is only a triplet state i.e. $\mathrm{T}_{1}$ lower than $S_{1}$ in energy for compounds 1 and 2 . In other words, no higher-lying triplet excited states are involved in the rISC processes.

Finally, we analyze the changes of reorganization energies ( $\left.\lambda_{\text {reorg}}\right)$, which can help us understand the radiationless processes either from $S_{1}$ to $T_{1}$ or from $T_{1}$ to $S_{1}$. The reorganization energy is calculated through the total Huang-Rhys factor $S$, which is collected as a sum of the Huang-Rhys factors of all vibrational frequencies $S_{j}$ via the following equation:

$$
S=\sum_{j}^{n} S_{j}=\sum_{j}^{n} \frac{\omega_{j}}{2 \hbar} \Delta Q_{j}^{2}
$$

where $\omega_{j}$ is the normal mode frequency of the $j$ th mode of the initial state and $\Delta Q_{j}$ is the normal mode displacement between the initial and the final states. The $\omega_{j}$ can be obtained via diagonalizing the mass-weighted Hessian matrix of the optimized initial state: $\boldsymbol{L}^{\mathrm{T}} \boldsymbol{H} \boldsymbol{L}=\boldsymbol{\omega}^{2}$; in the same time, the transformation matrix $\boldsymbol{L}$ is obtained.

In order to calculate $\Delta Q_{j}$, the following relationship for Cartesian coordinates is defined:

$$
\boldsymbol{q}_{\text {init }}=\boldsymbol{q}_{\mathrm{final}}+\Delta \boldsymbol{q}
$$

Table 3 Relative energy (eV) of PBE1PBE optimized structures of complexes 1 and 2 in crystal and their energy differences

\begin{tabular}{lll}
\hline & 1 & 2 \\
\hline $\mathrm{S}_{1}$ & 2.89 & 2.75 \\
$\mathrm{~T}_{1}$ & 2.74 & 2.66 \\
$\Delta E_{\mathrm{S}_{1}-\mathrm{T}_{1}}$ & 0.15 & 0.09
\end{tabular}

in which $\boldsymbol{q}_{\text {init }}$ and $\boldsymbol{q}_{\text {final }}$ represent mass-weighted Cartesian coordinates of initial and final states; then, the normal mode coordinates $\boldsymbol{Q}$ can be transformed from Cartesian coordinates $\boldsymbol{q}$ using the relation $\boldsymbol{Q}=\boldsymbol{L}^{\mathrm{T}} \boldsymbol{q}$. Finally, we arrive at the following equation:

$$
\boldsymbol{Q}_{\text {init }}=\boldsymbol{L}_{\text {init }}^{\mathrm{T}} \boldsymbol{L}_{\text {final }} \boldsymbol{Q}_{\text {final }}+\boldsymbol{L}_{\text {init }}^{\mathrm{T}} \Delta \boldsymbol{q}
$$

where $\boldsymbol{L}_{\text {final }}$ and $\boldsymbol{L}_{\text {init }}$ correspond to the transform matrices of the final and initial states that diagonalize the corresponding mass-weighted Hessian matrices. $\boldsymbol{L}_{\text {init }} \boldsymbol{L}_{\text {final }}^{\mathrm{T}}(=\boldsymbol{D})$ is called Duschinsky rotation matrix in the literature, so $\Delta \boldsymbol{Q}$ could be calculated by $\Delta \boldsymbol{Q}=\boldsymbol{L}_{\text {init }}^{\mathrm{T}} \Delta \boldsymbol{q}$. Once $S$ and $S_{j}$ are calculated, the reorganization energy

$$
\lambda_{\text {reorg }}=\sum_{j}^{n} \lambda_{\text {reorg }_{j}}=\sum_{j}^{n} S_{j} \omega_{j} \hbar
$$

can be calculated in a straightforward way.

From Table 2 , the reorganization energies $\lambda_{\text {reorg }}$ for compound 1 either from $S_{1}$ to $T_{1}(0.0256 \mathrm{eV})$ or from $T_{1}$ to $S_{1}$ $(0.0241 \mathrm{eV})$ are much close to each other. For compound 2 , the $\lambda_{\text {reorg }}$ values from $S_{1}$ to $T_{1}$ or from $T_{1}$ to $S_{1}$ are similar in crystal, $0.0108 \mathrm{eV}$ from $S_{1}$ to $T_{1} v s$. $0.0096 \mathrm{eV}$ from $T_{1}$ to $S_{1}$. The reorganization energies $\lambda_{\text {reorg }}$ of compound 1 either from $S_{1}$ to $T_{1}$ or from $T_{1}$ to $S_{1}$ are slightly larger than those of compound 2 in crystal phase. In addition, we have examined the distribution of the Huang-Rhys factors. Fig. S5† depicts the Huang-Rhys factor for each vibrational mode involved in the ISC and rISC processes of compounds $\mathbf{1}$ and $\mathbf{2}$ in crystal. The low-frequency vibrational modes related to the torsional motion of the dppb and dpppy groups are mainly responsible for these intersystem crossing processes between $S_{1}$ and $T_{1}$ (either ISC or rISC). Comparing these Huang-Rhys factors, one can find that the vibrational modes with large Huang-Rhys factors in the lowfrequency region are suppressed to certain extent in compound 2 . This is consistent with the results of $\lambda_{\text {reorg }}$ discussed above.

On the basis of SOC, $\Delta E_{\mathrm{ST}}$, and $\lambda_{\text {reorg, }}$, we have calculated the related intersystem crossing rates $k_{\text {ISC }}$ and $k_{\text {rISC }}$ of these two $\mathrm{Cu}(\mathrm{I})$ dimers in crystal. The $k_{\text {ISC }}$ and $k_{\text {rISC }}$ values of compound 2 are larger than those of compound $\mathbf{1}$ at room temperature. For example, the $k_{\mathrm{ISC}}$ and $k_{\mathrm{rISC}}$ values of compound $2\left(2.34 \times 10^{9}\right.$ and $\left.3.36 \times 10^{7} \mathrm{~s}^{-1}\right)$ are larger than those of compound $1(8.25 \times$ $10^{8}$ and $6.27 \times 10^{5} \mathrm{~s}^{-1}$ ), respectively. This change trend is in good agreement with that of involved SOC values (see Table 2). Moreover, the rates $k_{\text {rISC }}$ of either compounds $\mathbf{1}$ or $\mathbf{2}$ are smaller than their forward intersystem crossing rates $k_{\text {ISC }}$ in crystal. For example, the $k_{\text {rISC }}$ and $k_{\text {ISC }}$ values are predicted to be $6.27 \times 10^{5}$ $\left[3.36 \times 10^{7}\right]$ vs. $8.25 \times 10^{8}\left[2.34 \times 10^{9} \mathrm{~s}^{-1}\right]$ for 1 [2]. This is because the forward ISC process is energetically favorable whereas the reverse one is merely active when the thermal energy provided by the temperature can overcome the related reverse barriers. Finally, we have checked the temperature effects on these intersystem crossing rates $k_{\text {ISC }}$ and $k_{\text {rISC }}$ (see Fig. 6). Obviously, both $k_{\text {ISC }}$ and $k_{\text {rISC }}$ rates of compounds 1 and 2 increase with higher temperature, which is caused by the fact that more vibrationally excited states are involved in the 


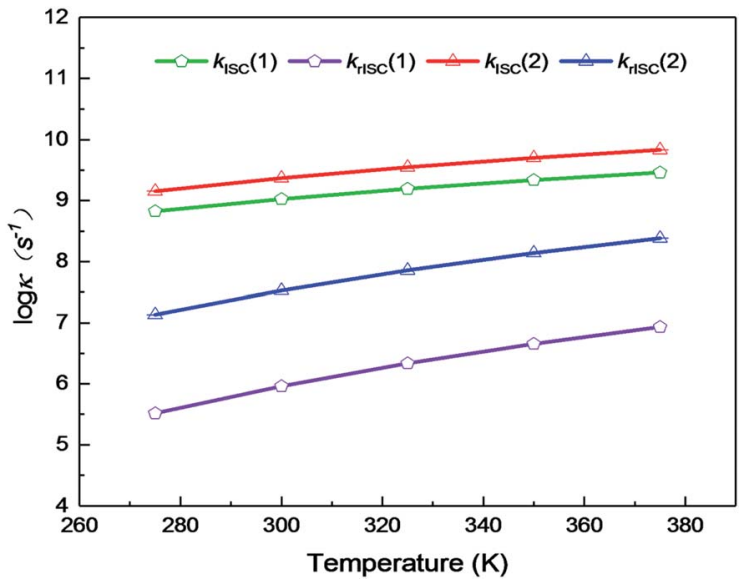

Fig. 6 Temperature dependence of ISC and rISC rates of complexes 1 and 2 from 275 to $375 \mathrm{~K}$.

intersystem crossing processes when the temperature increases. ${ }^{58}$ Furthermore, one can see that the reverse intersystem crossing rate constants $k_{\text {rISC }}$ are more sensitive to the temperature than those of the forward ones $k_{\text {ISC }}$ in the temperature range of 275 to $375 \mathrm{~K}$.

From above eqn (1) and (2), it is clear that $k_{\text {ISC }}$ and $k_{\text {rISC }}$ rate constants are dependent on not only SOC values but also $(\Delta E+$ $\left.\lambda_{\text {reorg }}\right)^{2}$. Fig. 7 shows the relationship of the forward and reverse ISC rate constants and $\Delta E$ for compounds 1 and 2 in crystal. In the equations, $\Delta E$ is defined as the difference between adiabatic energies of the final and initial states. For the reverse ISC processes from $\mathrm{T}_{1}$ to $\mathrm{S}_{1}, \Delta E_{\mathrm{ST}}=\left(E_{\mathrm{S}_{1}}-E_{\mathrm{T}_{1}}\right)$ is positive for our studied systems, so $k_{\mathrm{rISC}}$ decreases upon increasing $\Delta E$ because $\lambda_{\text {reorg }}$ is a fixed positive value. By contrast, $k_{\mathrm{ISC}}$ is affected by both $\Delta E$ and $\lambda_{\text {reorg }}$ through $\left(\Delta E+\lambda_{\text {reorg }}\right)^{2}$ because $\Delta E_{\mathrm{TS}}=\left(E_{\mathrm{T}_{1}}-\mathrm{E}_{\mathrm{S}_{1}}\right)$ is negative for our studied systems. Specifically, when $\Delta E_{\mathrm{ST}}$ is larger than the reorganization energy $\lambda_{\text {reorg }}, k_{\text {ISC }}$ decreases upon increasing $\Delta E_{\mathrm{TS}}$. Because $\Delta E_{\mathrm{TS}}=-\Delta E_{\mathrm{ST}}, k_{\mathrm{ISC}}$ is found to decrease with decreasing $\Delta E_{\mathrm{ST}}$. More interestingly, the curvatures of parabolic functions for the $k_{\mathrm{ISC}}$ and $k_{\mathrm{rISC}}$ rate constants of compound 1 as a function of $\Delta E_{\mathrm{ST}}$ are slightly smaller than those of compound 2 (see Fig. 7). This can be understood based on eqn (2) and (3). The logarithmic function of the rate constant $k$ can be rewritten as follows

$$
\ln k=\text { constant }-\frac{\left(\Delta E+\lambda_{\text {reorg }}\right)^{2}}{4 \lambda_{\text {reorg }} k_{\mathrm{B}} T}
$$

in which

$$
\text { constant }=\ln \left(\frac{1}{\hbar}\left|H_{\mathrm{if}}\right|^{2} \sqrt{\frac{\pi}{\lambda_{\text {reorg }} k_{\mathrm{B}} T}}\right)
$$

From this equation, it is clear that the function curvature is proportional to $|1 / \lambda|$ when the temperature is fixed. Because the $\lambda$ values for compound $\mathbf{1}$ are larger than those of compound $\mathbf{2}$, as shown in Table 2, the former curvatures are smaller than the latter ones. In addition, one can find that the parabolic peaks are always at the points of $\Delta E=-\lambda_{\text {reorg }}$ where the logarithmic function in eqn (7) achieves a maximum value.

3.5.2 Radiative rates. As mentioned in previous works, ${ }^{63}$ highly luminescent TADF materials should have an efficient radiative decay rate (more than $10^{6} \mathrm{~s}^{-1}$ ) to overcome competitive nonradiative pathway from $S_{1}$ to $S_{0}$. Accordingly, we have calculated the rate constants of fluorescence $\left(k_{\mathrm{r}}^{\mathrm{F}}\right)$ and phosphorescence $\left(k_{\mathrm{r}}^{\mathrm{P}}\right)$ according to the following formula using the ADF software:

$$
k_{\mathrm{r}}^{\mathrm{F} / \mathrm{P}}=\frac{2 \pi \nu^{2} e^{2}}{\varepsilon_{0} m c^{3}} f_{\mathrm{S}_{1} \text { or } \mathrm{T}_{1} \rightarrow \mathrm{S}_{0}}
$$

in which $\nu$ is the emission energy; $e$ is the elementary electric charge; $\varepsilon_{0}$ is the vacuum permittivity; $m$ is the mass of electrons; $c$ is the speed of light; and $f_{\mathrm{S}_{1} \text { or } \mathrm{T}_{1} \rightarrow \mathrm{s}_{0}}$ is the oscillator strength for $\mathrm{S}_{1} \rightarrow \mathrm{S}_{0}$ or $\mathrm{T}_{1} \rightarrow \mathrm{S}_{0}$ radiative transition.
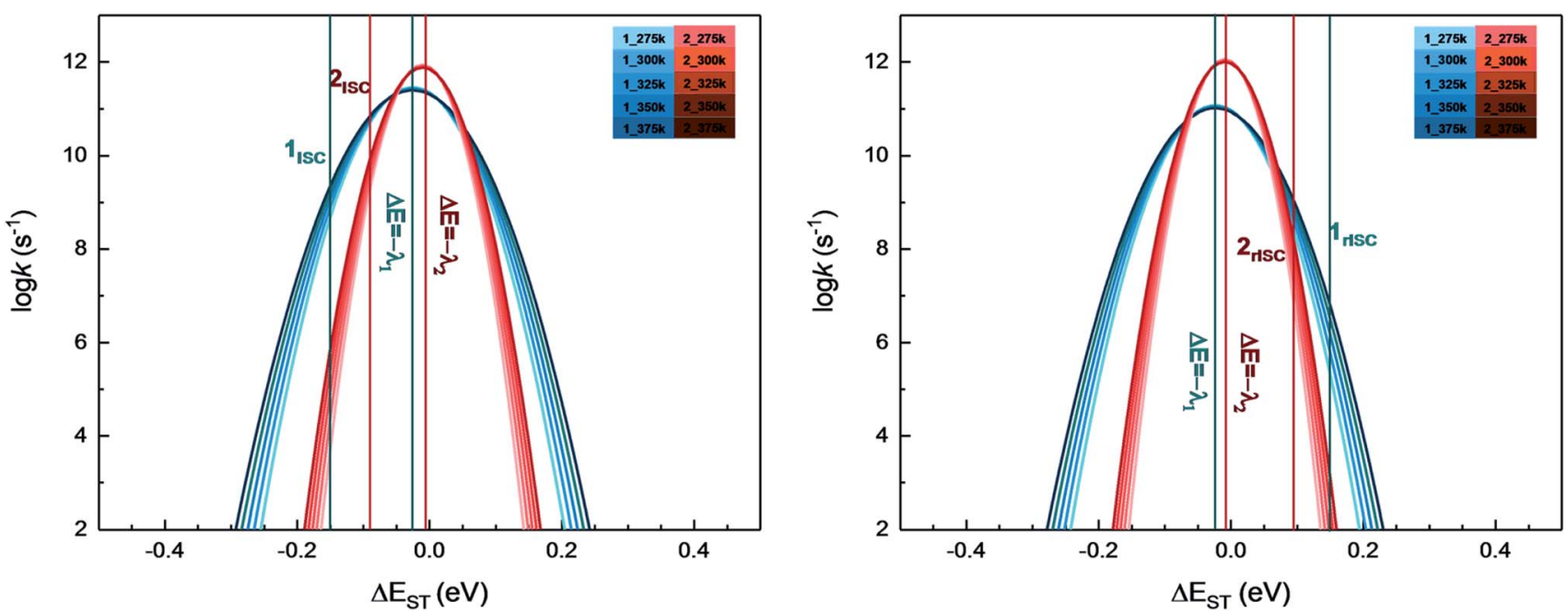

Fig. 7 Forward (left) and reverse (right) intersystem crossing rate constants ISC and rISC as a function of $\Delta E_{\mathrm{ST}}$ at different temperatures of complexes 1 (blue) and 2 (red). 
From Table 2, it can be found that the fluorescence and phosphorescence emission rates of compound 2 are smaller than those of compound 1 in crystal. The $k_{\mathrm{r}}^{\mathrm{F}}$ rate of compound 2 is $0.33 \times 10^{6} \mathrm{~s}^{-1}$, which is smaller than $3.91 \times 10^{6} \mathrm{~s}^{-1}$ of compound 1. Moreover, one can see that the phosphorescence emission rates are much smaller than the fluorescence emission rates ( $c a .10^{3}$ vs. $\left.10^{6} \mathrm{~s}^{-1}\right)$. Our presently calculated fluorescence radiative rates $k_{\mathrm{r}}^{\mathrm{F}}$ are in good agreement with experiments, in which they are estimated to be $0.25 \times 10^{6}$ and $0.12 \times 10^{6} \mathrm{~s}^{-1}$ for compounds 1 and 2 , respectively. These efficient radiative decay rates may overcome competitive nonradiative pathway from $S_{1}$ to $S_{0}$ to enable TADF.

\subsection{TADF mechanism}

The existence of TADF indicates not only that the $S_{1} / T_{1}$ SOC should be significant for efficient reverse ISC but also that the $\mathrm{S}_{1}-\mathrm{T}_{1}$ energy gap has to be small enough so that thermal energy can overcome this gap efficiently. In the following, we will discuss the TADF mechanism of compounds 1 and 2.

A three-state model of the $S_{0}, S_{1}$, and $T_{1}$ states is enough and used to study the TADF mechanism in these two $\mathrm{Cu}(\mathrm{I})$ dimer compounds because the $\mathrm{T}_{2}$ state is energetically higher than the $\mathrm{S}_{1}$ and $\mathrm{T}_{1}$ states at either $\mathrm{S}_{1}$ or $\mathrm{T}_{1}$ minima as discussed above. Fig. 8 summaries a reasonable speculation about the TADF working mechanism of compound 1 . This compound can effectively convert its $S_{1}$ to $T_{1}$ states with an ISC rate constant of $8.25 \times 10^{8} \mathrm{~s}^{-1}$; importantly, the rISC process back to the $\mathrm{S}_{1}$ state is also very faster at the room temperature $\left(6.27 \times 10^{5} \mathrm{~s}^{-1}\right)$. These ISC and rISC rates are two orders of magnitude larger than the fluorescence and phosphorescence emission rates from the $S_{1}$ and $\mathrm{T}_{1}$ states $\left[k_{\mathrm{ISC}}\left(10^{8} \mathrm{~s}^{-1}\right)>k_{\mathrm{r}}^{\mathrm{F}}\left(10^{6} \mathrm{~s}^{-1}\right), k_{\mathrm{rISC}}\left(10^{5}\right.\right.$ $\left.\mathrm{s}^{-1}\right)>k_{\mathrm{r}}^{\mathrm{P}}\left(10^{3} \mathrm{~s}^{-1}\right)$; see Table 2]. In addition, the phosphorescence emission rates are overall about 3 orders of magnitude smaller than the fluorescence emission rates. Thereby, compound 1 mainly fluoresces from the $S_{1}$ state because the $T_{1}$ population can be quickly transferred back to the $S_{1}$ state through the fast rISC process. The internal conversion (IC) process from $S_{1}$ to $S_{0}$ and the ISC process from $T_{1}$ to $S_{0}$ are much slower due to huge energy gaps between $S_{1}$ and $S_{0}$ and between $\mathrm{T}_{1}$ and $\mathrm{S}_{0}$, so these nonradiative decay rates are neglected in our model. ${ }^{64}$ Even though the $k_{\mathrm{r}}^{\mathrm{F}}$ rate of compound 2 is smaller than that of compound $\mathbf{1}$, the TADF mechanism of 2 is similar to that

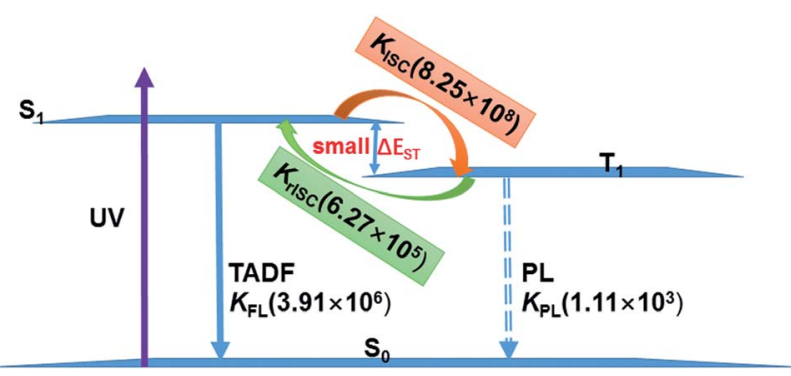

Fig. 8 TADF working mechanism of complex 1 including related radiative and radiationless rates calculated by our present theoretical studies. of $\mathbf{1}$. The present analysis gives in-depth understanding on the TADF properties of the two dinuclear Cu(I) iodide complexes. ${ }^{9}$

The present results for the TADF of dinuclear $\mathrm{Cu}(\mathrm{I})$ iodide complexes also show that structural rigidity around the central $\mathrm{Cu}(\mathrm{I})$ atom is important. First, it benefits rapid intersystem crossing processes between singlets and triplets. Second, efficient deactivation pathways due to structural distortion are effectively suppressed. For example, the emission of dinuclear $\mathrm{Cu}(\mathrm{I})$ complexes with less-bulky ligands, i.e. $\left[\left\{\mathrm{Cu}\left(\mathrm{PPh}_{3}\right)_{2}(-\right.\right.$ $\left.\left.\left.\mathrm{H}_{2} \mathrm{O}\right)\right\}(\mu-\mathrm{MeOpyz})\left\{\mathrm{Cu}\left(\mathrm{PPh}_{3}\right)_{2}\left(\mathrm{H}_{2} \mathrm{O}\right)\right\}\right]\left(\mathrm{BF}_{4}\right)_{2}$ with $\mathrm{PPh}_{3}=$ triphenylphosphine and MeOpyz = 2-methoxypyrazine, is observed at $580 \mathrm{~nm}$ with a remarkably lower quantum yield of 0.05 , which has been proved due to efficient excited-state deactivation through structural distortion around the $\mathrm{Cu}$ atom from tetrahedral to quasi-square-planar coordination structures. ${ }^{56}$

Finally, TADF is very sensitive to subtle structural changes of emitting materials. Our studied two compounds are not similar because they have distinctly different ligands: one is related to pyridine and the other is related to benzene. Both ligands indeed brings us significant differences. First, the energy gap becomes smaller in compound $\mathbf{2}$ than that of compound $\mathbf{1}$, which is caused by the introduction of the pyridyl $\mathrm{N}$ atom with large electronegativity to the aromatic ring that stabilizes the $\pi^{*}$ orbitals. Second, the introduction of the $\mathrm{N}$ atom to the crosslinking phenyl groups of the diphosphine ligands in compound 2 greatly shifts the emission from bright-greenishblue $(497 \mathrm{~nm})$ to yellow $(548 \mathrm{~nm})$. Third, the $k_{\mathrm{ISC}}$ and $k_{\mathrm{rISC}}$ values of compound 2 are larger than those of compound 1 at room temperature. For example, the $k_{\text {ISC }}$ and $k_{\text {rISC }}$ values of compound 2 are larger than those of compound 1 , respectively (see Table 2). Fourth, the fluorescence and phosphorescence emission rates of compound 2 are smaller than those of compound 1 in crystal.

It should be noted that the TADF mechanism of copperbased organometallic compounds is rather different from those of pure organic TADF emitters. Recently, Penfold et al. have summarized many efficient organic TADF emitters and related TADF mechanisms. ${ }^{65}$ For example, different D-A-D molecules with very similar energy gaps exhibit large variations in $k_{\text {rISC }}$. They found that luminescence could be switched from TADF to phosphorescence by sterically hindering the motion of $\mathrm{D}$ and $\mathrm{A}$ group. Interested readers are referred to this literature. ${ }^{65}$

\section{Conclusions}

The structures, excited properties, and luminescence of two dinuclear $\mathrm{Cu}(\mathrm{I})$ complexes with dppb and dpppy ligands $\left[\mathrm{Cu}_{2}(\mu-\right.$ $\left.\mathrm{I})_{2}(\mathrm{dppb})_{2}\right](\mathbf{1})$ and $\left[\mathrm{Cu}_{2}(\mu-\mathrm{I})_{2}(\mathrm{dpppy})_{2}\right]$ (2) as potential TADF emitters have been comprehensively studied by means of combined QM/MM calculations. On the basis of ground and excited-state geometries we have found that the $S_{1}$ and $T_{1}$ states have very small energy gaps $\Delta E_{\mathrm{ST}}$, less than $0.15 \mathrm{eV}$, which makes the forward and reverse intersystem crossing ISC and rISC processes between $S_{1}$ and $T_{1}$ much efficient. We have also found that both ISC and rISC processes are much faster than the corresponding fluorescence and phosphorescence radiative 
processes $\left[k_{\mathrm{ISC}}\left(10^{8} \mathrm{~s}^{-1}\right)>k_{\mathrm{r}}^{\mathrm{F}}\left(10^{6} \mathrm{~s}^{-1}\right), k_{\mathrm{rISC}}\left(10^{5} \mathrm{~s}^{-1}\right)>k_{\mathrm{r}}^{\mathrm{P}}\left(10^{3}\right.\right.$ $\left.\mathrm{s}^{-1}\right)$ ]. Since the reverse rISC rates are much faster than the phosphorescence emission rates, the $T_{1}$ population can be quickly transferred to the $\mathrm{S}_{1}$ state leading to a delay fluorescence emission. Through analyzing the Huang-Rhys factors we have found that the low-frequency vibrational modes related to the torsional motion of the dppb and dpppy groups are mainly in charge of these intersystem crossing processes ISC or rISC. Our present calculations not only elucidate recent experimental phenomena but also help understand, and design similar TADF emitters, e.g. with rigid ligands to inhibit structural distortions of emitting states and nonradiative processes, etc.

\section{Conflicts of interest}

The authors declared that they have no conflicts of interest to this work.

\section{Acknowledgements}

This work was supported by the National Natural Science Foundation of China (G. C. 21522302) and China Postdoctoral Science Foundation (2018M641243); G. C. is also grateful for the financial support from "Fundamental Research Funds for Central Universities".

\section{References}

1 J. Gibson, A. P. Monkman and T. J. Penfold, ChemPhysChem, 2016, 17, 2956.

2 G. Baryshnikov, B. Minaev and H. Ågren, Chem. Rev., 2017, 117, 6500 .

3 J. Föller, M. Kleinschmidt and C. M. Marian, Inorg. Chem., 2016, 55, 7508.

4 X.-K. Chen, S.-F. Zhang, J.-X. Fan and A.-M. Ren, J. Phys. Chem. C, 2015, 119, 9728.

5 Q. Peng, D. Fan, R. Duan, Y. Yi, Y. Niu, D. Wang and Z. Shuai, J. Phys. Chem. C, 2017, 121, 13448.

6 A. Stoïanov, C. Gourlaouen, S. Vela and C. Daniel, J. Phys. Chem. A, 2018, 122, 1413.

7 J. Fan, L. Lin and C.-K. Wang, J. Mater. Chem. C, 2017, 5, 8390.

8 T. Vikramaditya, M. Saisudhakar and K. Sumithra, RSC Adv., 2016, 6, 37203.

9 Y. Okano, H. Ohara, A. Kobayashi, M. Yoshida and M. Kato, Inorg. Chem., 2016, 55, 5227.

10 G. Blasse and D. R. McMillin, Chem. Phys. Lett., 1980, 70, 1.

11 Y. G. Ma, W.-H. Chan, X.-M. Zhou and C.-M. Che, New J. Chem., 1999, 23, 263.

12 J. L. Markus, M. Z. Danie, S. Alexander, B. Thomas, V. Daniel and Y. Hartmut, Top. Curr. Chem., 2016, 374, 25.

13 Y. Tao, K. Yuan, T. Chen, P. Xu, H. Li, R. Chen, C. Zheng, L. Zhang and W. Huang, Adv. Mater., 2014, 26, 7931.

14 A. J. M. Miller, J. L. Dempsey and J. C. Peters, Inorg. Chem., 2007, 46, 7244.

15 J. Chen, T. Teng, J.-Y. Wang, L. Kang, X.-L. Chen, L.-J. Xu, R. Yu and C.-Z. Lu, Eur. J. Inorg. Chem., 2016, 2016, 3036.
16 A. Tsuboyama, K. Kuge, M. Furugori, S. Okada, M. Hoshino and K. Ueno, Inorg. Chem., 2007, 46, 1992.

17 H. Araki, K. Tsuge, Y. Sasaki, S. Ishizaka and N. Kitamura, Inorg. Chem., 2007, 46, 10032.

18 J. C. Deaton, S. C. Switalski, D. Y. Kondakov, R. H. Young, T. D. Pawlik, D. J. Giesen, S. B. Harkins, A. Miller, S. F. Mickenberg and J. C. Peters, J. Am. Chem. Soc., 2010, 132, 9499.

19 D. M. Zink, M. Bächle, T. Baumann, M. Nieger, M. Kühn, C. Wang, W. Klopper, U. Monkowius, T. Hofbeck, H. Yersin and S. Bräse, Inorg. Chem., 2013, 52, 2292.

20 M. J. Leitl, F.-R. Küchle, H. A. Mayer, L. Wesemann and H. Yersin, J. Phys. Chem. A, 2013, 117, 11823.

21 H. Araki, K. Tsuge, Y. Sasaki, S. Ishizaka and N. Kitamura, Inorg. Chem., 2005, 44, 9667.

22 G. Li, R. S. Nobuyasu, B. Zhang, Y. Geng, B. Yao, Z. Xie, D. Zhu, G. Shan, W. Che, L. Yan, Z. Su, F. B. Dias and M. R. Bryce, Chem.-Eur. J., 2017, 23, 11761.

23 J. P. Perdew, K. Burke and M. Ernzerhof, Phys. Rev. Lett., 1996, 77, 3865.

24 B. Delley, Phys. Rev. B: Condens. Matter Mater. Phys., 2002, 66, 155125.

25 S. Grimme, J. Antony, S. Ehrlich and H. Krieg, J. Chem. Phys., 2010, 132, 154104.

26 B. Delley, J. Chem. Phys., 1990, 92, 508.

27 B. Delley, J. Phys. Chem., 1996, 100, 6107.

28 B. Delley, J. Chem. Phys., 2000, 113, 7756.

29 F. Maseras and K. J. Morokuma, J. Comput. Chem., 1995, 16, 1170.

30 T. Vreven, K. Morokuma, Ö. Farkas, H. B. Schlegel and M. J. Frisch, J. Comput. Chem., 2003, 24, 760.

31 A. K. Rappé, C. J. Casewit, K. S. Colwell, W. A. Goddard III and W. M. Skiff, J. Am. Chem. Soc., 1992, 114, 10024.

32 Y.-J. Gao, W.-K. Chen, Z.-R. Wang, W.-H. Fang and G. L. Cui, Phys. Chem. Chem. Phys., 2018, 20, 24955.

33 L. W. Chung, W. M. C. Sameera, R. Ramozzi, A. J. Page, M. Hatanaka, G. P. Petrova, T. V. Harris, X. Li, Z. Ke, F. Y. Liu, H.-B. Li, L. Ding and K. Morokuma, Chem. Rev., 2015, 115, 5678.

34 J. Fan, Y. Zhang, Y. Zhou, L. Lin and C.-K. Wang, J. Phys. Chem. C, 2018, 122, 2358.

35 M. Ernzerhof and G. E. Scuseria, J. Chem. Phys., 1999, 110, 5029.

36 C. Adamo and V. Barone, J. Chem. Phys., 1999, 110, 6158.

37 M. A. L. Marques, C. A. Ullrich, F. Nogueira, A. Rubio, K. Burke and E. K. U. Gross, Time-dependent Density Functional Theory, Springer, 2006.

38 D. Andrae, U. Häußermann, M. Dolg, H. Stoll and H. Preuß, Theor. Chem. Acc., 1990, 77, 123.

39 J. M. L. Martin and A. Sundermann, J. Chem. Phys., 2001, 114, 3408.

40 R. Ditchfield, W. J. Hehre and J. A. Pople, J. Chem. Phys., 1971, 54, 724.

41 P. C. Hariharan and J. A. Pople, Theor. Chem. Acc., 1973, 28, 213.

42 M. J. Frisch, G. W. Trucks, H. B. Schlegel, G. E. Scuseria, M. A. Robb, J. R. Cheeseman, G. Scalmani, V. Barone, 
B. Mennucci, G. A. Petersson, H. Nakatsuji, M. Caricato, X. Li, H. P. Hratchian, A. F. Izmaylov, J. Bloino, G. Zheng, J. L. Sonnenberg, M. Hada, M. Ehara, K. Toyota, R. Fukuda, J. Hasegawa, M. Ishida, T. Nakajima, Y. Honda, O. Kitao, H. Nakai, T. Vreven, J. A. Montgometry Jr, J. E. Peralta, F. Ogliaro, M. Bearpark, J. J. Heyd, E. Brothers, K. N. Kudin, V. N. Staroverov, R. Kobayashi, J. Normand, K. Raghavachari, A. Rendell, J. C. Burant, S. S. Iyengar, J. Tomasi, M. Cossi, N. Rega, J. M. Millam, M. Klene, J. E. Knox, J. B. Cross, V. Bakken, C. Adamo, J. Jaramillo, R. Gomperts, R. E. Stratmann, O. Yazyev, A. J. Austin, R. Cammi, C. Pomelli, J. W. Ochterski, R. L. Martin, K. Morokuma, V. G. Zakrzewski, G. A. Voth, P. Salvador, J. J. Dannenberg, S. Dapprich, A. D. Daniels, O. Farkas, J. B. Foresman, J. V. Ortiz, J. Cioslowski and D. J. Fox, Gaussian 09, Revision D.01, Gaussian, Inc., Wallingford CT, 2013.

43 M. J. Frisch, G. W. Trucks, H. B. Schlegel, G. E. Scuseria, M. A. Robb, J. R. Cheeseman, G. Scalmani, V. Barone, G. A. Petersson, H. Nakatsuji, X. Li, M. Caricato, A. V. Marenich, J. Bloino, B. G. Janesko, R. Gomperts, B. Mennucci, H. P. Hratchian, J. V. Ortiz, A. F. Izmaylov, J. L. Sonnenberg, D. Williams-Young, F. Ding, F. Lipparini, F. Egidi, J. Goings, B. Peng, A. Petrone, T. Henderson, D. Ranasinghe, V. G. Zakrzewski, J. Gao, N. Rega, G. Zheng, W. Liang, M. Hada, M. Ehara, K. Toyota, R. Fukuda, J. Hasegawa, M. Ishida, T. Nakajima, Y. Honda, O. Kitao, H. Nakai, T. Vreven, K. Throssell, J. A. Montgometry Jr, J. E. Peralta, F. Ogliaro, M. J. Bearpark, J. J. Heyd, E. N. Brothers, K. N. Kudin, V. N. Staroverov, T. A. Keith, R. Kobayashi, J. Normand, K. Raghavachari, A. P. Rendell, J. C. Burant, S. S. Iyengar, J. Tomasi, M. Cossi, J. M. Millam, M. Klene, C. Adamo, R. Cammi, J. W. Ochterski, R. L. Martin, K. Morokuma, O. Farkas, J. B. Foresman and D. J. Fox, Gaussian 16, Revision A. 03, Gaussian, Inc., Wallingford CT, 2016.

44 G. te Velde, F. M. Bickelhaupt, E. J. Baerends, C. Fonseca Guerra, S. J. A. van Gisbergen, J. G. Snijders and T. Ziegler, J. Comput. Chem., 2001, 22, 931.

45 C. Fonseca Guerra, J. G. Snijders, G. te Velde and E. J. Baerends, Theor. Chem. Acc., 1998, 99, 391.

46 E. J. Baerends, T. Ziegler, A. J. Atkins, J. Autschbach, D. Bashford, A. Bérces, F. M. Bickelhaupt, C. Bo, P. M. Boerritger, L. Cavallo, D. P. Chong, D. V. Chulhai, L. Deng, R. M. Dickson, J. M. Dieterich, D. E. Ellis, M. van Faassen, L. Fan, T. H. Fischer, C. Fonseca Guerra, M. Franchini, A. Ghysels, A. Giammona, S. J. A. van Gisbergen, A. W. Götz, J. A. Groeneveld, O. V. Gritsenko, M. Grüning, S. Gusarov, F. E. Harris, P. van den Hoek, C. R. Jacob, H. Jacobsen, L. Jensen, J. W. Kaminski, G. van
Kessel, F. Kootstra, A. Kovalenko, M. V. Krykunov, E. van Lenthe, D. A. McCormack, A. Michalak, M. Mitoraj, S. M. Morton, J. Neugebauer, V. P. Nicu, L. Noodleman, V. P. Osinga, S. Patchkovskii, M. Pavanello, C. A. Peeples, P. H. T. Philipsen, D. Post, C. C. Pye, W. Ravenek, J. I. Rodríguez P. Ros, R. Rüger, P. R. T. Schipper, H. van Schoot, G. Schreckenbach, J. S. Seldenthuis, M. Seth, J. G. Snijders, M. Solà, M. Swart, D. Swerhone, G. te Velde, P. Vernooijs, L. Versluis, L. Visscher, O. Visser, F. Wang, T. A. Wesolowski, E. M. van Wezenbeek, G. Wiesenekker, S. K. Wolff, T. K. Woo and A. L. Yakovlev, ADF2016, SCM, Theoretical Chemistry, Vrije Universiteit, Amsterdam, The Netherlands, https://www.scm.com.

47 E. van Lenthe and E. J. Baerends, J. Comput. Chem., 2003, 24, 1142.

48 D. P. Chong, E. van Lenthe, S. van Gisbergen and E. J. Baerends, J. Comput. Chem., 2004, 25, 1030.

49 F. Wang and T. Ziegler, J. Chem. Phys., 2005, 123, 154102.

50 E. van Lenthe, E. J. Baerends and J. G. Snijders, J. Chem. Phys., 1994, 101, 9783.

51 E. van Lenthe, R. van Leeuwen, E. J. Baerends and J. G. Snijders, Int. J. Quantum Chem., 1996, 57, 281.

52 L. Kang, J. Chen, T. Teng, X.-L. Chen, R. Yu and C.-Z. Lu, Dalton Trans., 2015, 44, 11649.

53 A. Kobayashi, K. Komatsu, H. Ohara, W. Kamada, Y. Chishina, K. Tsuge, H.-C. Chang and M. Kato, Inorg. Chem., 2013, 52, 13188.

54 P. Aslanidis, P. J. Cox, S. Divanidis and A. C. Tsipis, Inorg. Chem., 2002, 41, 6875.

55 A. Kobayashi, Y. Yoshida, M. Yoshida and M. Kato, Chem.Eur. J., 2018, 24, 1.

56 A. Kobayashi, R. Arata, T. Ogawa, M. Yoshida and M. Kato, Inorg. Chem., 2017, 56, 4280.

57 Y.-J. Gao, Z.-R. Wang, W.-K. Chen, W.-H. Fang and G. L. Cui, Chem. Phys., 2018, 515, 692.

58 R. A. Marcus, J. Phys. Chem., 1963, 67, 853.

59 R. A. Marcus and N. Sutin, Biochim. Biophys. Acta, 1985, 811, 265.

60 I. Prigogine and S. A. Rice, Advances in Chemical Physics, John Wiley \& Sons, 2003.

61 Y. X. Liu, M. S. Lin and Y. Zhao, J. Phys. Chem. A, 2017, 121, 1145.

62 J.-L. Brédas, D. Beljonne, V. Coropceanu and J. Cornil, Chem. Rev., 2014, 104, 4791.

63 Y. Gao, T. Su, L. Zhao, Y. Geng, Y. Wu, M. Zhang and Z. M. Su, Org. Electron., 2017, 50, 70.

64 H. Lin, X. P. Chang, D. Yan, W.-H. Fang and G. L. Cui, Chem. Sci., 2017, 8, 2086.

65 T. J. Penfold, F. B. Dias and A. P. Monkman, Chem. Commun., 2018, 54, 3926. 